\title{
Longitudinal Change in High-Cost Prosocial Behaviors of Defending and Including during the Transition to Adulthood
}

\author{
Laura M. Padilla-Walker \\ Brigham Young University, laura_walker@byu.edu \\ Madison K. Memmott-Elison \\ Matthew G. Nielson
}

Follow this and additional works at: https://scholarsarchive.byu.edu/facpub

Part of the Social and Behavioral Sciences Commons

\section{Original Publication Citation}

Padilla-Walker, L. M., *Memmott-Elison, M. K., \& *Nielson, M. G. (2018). Longitudinal change in high-cost prosocial behaviors of defending and including during the transition to adulthood. Journal of Youth and Adolescence, 47, 1853-1865

\section{BYU ScholarsArchive Citation}

Padilla-Walker, Laura M.; Memmott-Elison, Madison K.; and Nielson, Matthew G., "Longitudinal Change in High-Cost Prosocial Behaviors of Defending and Including during the Transition to Adulthood" (2018). Faculty Publications. 4958.

https://scholarsarchive.byu.edu/facpub/4958

This Peer-Reviewed Article is brought to you for free and open access by BYU ScholarsArchive. It has been accepted for inclusion in Faculty Publications by an authorized administrator of BYU ScholarsArchive. For more information, please contact ellen_amatangelo@byu.edu. 


\title{
Longitudinal Change in High-Cost Prosocial Behaviors of Defending and Including during the Transition to Adulthood
}

\author{
Laura M. Padilla-Walker ${ }^{1} \cdot$ Madison K. Memmott-Elison ${ }^{1} \cdot$ Matthew G. Nielson $^{1}$
}

Received: 3 May 2018 / Accepted: 19 May 2018 / Published online: 25 June 2018

(c) Springer Science+Business Media, LLC, part of Springer Nature 2018

\begin{abstract}
Despite high profile examples that are highlighted in the popular media, we know little about high-cost prosocial behaviors such as defending and including, and how these behaviors might change over time and vary by individual. Thus, this study explored defending and including behaviors across the transition to adulthood by assessing growth and profiles of these high-cost prosocial behaviors over a four-year time span. In addition the study explored gender, emotional (sympathy), cognitive (personal values), individual (self-esteem), and relational (maternal warmth) factors during adolescence that predicted profiles of defending and including during the transition to adulthood. Participants were 469 individuals (52\% female, 70\% European American) who participated at four time points (ages 18-21). Growth curve analyses showed that defending and including behaviors decreased slightly across the transition to adulthood and these behaviors tended to vary as a function of the target of the behavior. Latent profile analyses revealed three groups at each age, one with low, one with medium, and one with high levels of defending and including. The discussion focused on the prevalence and change in defending and including behaviors during the transition to adulthood, as well as the variability that exists in high-cost behavioral profiles.
\end{abstract}

Keywords Prosocial behavior $\cdot$ High-cost $\cdot$ Defending $\cdot$ Including

\section{Introduction}

The transition to adulthood is a unique time period during which young people are exploring and engaging in a multiplicity of positive behaviors, including high-cost prosocial behaviors such as defending and including others. The news has highlighted relatively recent examples of teens and young adults coming to the defense of minority groups, such as youth who protested violence against African Americans in Baltimore in 2015 (see Hart and VanGoethem 2017) and those advocating for the inclusion of minority individuals (e.g., women, LGBTQ; Watson 2014). There are also historical examples of youth involved in high-cost prosocial behaviors, such as the Student Nonviolent Coordinating Committee (SNCC, chaired by John Lewis), which was integral to the civil rights movement (Lewis and

Laura M. Padilla-Walker

laura_walker@byu.edu

1 School of Family Life, Brigham Young University, 2071 JFSB, Provo, UT 84602, USA
D’Orso 1999); and the White Rose, which was a nonviolent group started by a professor and a group of students at the University of Munich in the defense of Jews and in opposition of the Nazi regime during WWII (Gill 1994). Thus, defending and including behaviors may not be unique to this generation, but both historically and recently, teenagers and young adults are high profile participants.

While separate literatures exist to some degree to explore defending and including (or excluding) behaviors, recent research (Nielson et al. 2017) argues that these behaviors can be considered high-cost prosocial behaviors (voluntary behavior meant to benefit others; Eisenberg et al. 2015) that we know relatively little about, but that might be prevalent for both young adult men and women. For many, the transition to adulthood is replete with expanded opportunities to interact with strangers (through work or college experiences), make new friends, and redefine relationships with parents. These adjustments, along with educational experiences for young people who attend college or technical school, may provide unique opportunities to understand the plight of others in a setting where there are few constraints against acting to help others. Given the high-cost nature of these behaviors, as well as the prevalence of high 
profile examples of both defending and including during late adolescence and emerging adulthood, research is needed to shed light on developmental patterns and antecedents of defending and including. Are these prosocial behaviors a reflection that this generation has high political and civic engagement that is also reflected in their day to day defending (e.g., defending a sibling against a bully) and including behaviors (e.g., helping an ostracized peer feel part of the group), or are these types of prosocial behaviors relatively rare, despite the media attention that highlights youth involvement? The current study explored (1) the prevalence and longitudinal change in defending and including behaviors toward multiple targets during the transition to adulthood, (2) profiles of young adults who might show differing patterns of defending and including behaviors, and (3) correlates of defending and including profiles during the transition to adulthood.

\section{The Multidimensional Nature of Prosocial Behavior}

Recent research has sought to study prosocial behavior from a multidimensional perspective by analyzing different targets of prosocial behavior (e.g., family members, friends, and strangers; Padilla-Walker and Carlo 2014) as well as types of prosocial behavior (e.g., emotional support, helping, and sharing; Carlo and Randall 2002; Fortuna and Knafo 2014; Zimmer-Gembeck et al. 2005). This is important because studying different targets and types of prosocial behavior leads to a greater understanding of who youth help and the unique and diverse ways in which they help.

\section{Targets of prosocial behavior}

Research shows that emerging adults are taking more time transitioning to adulthood and therefore still rely on their family of origin for resources and support (Settersten and Ray 2010). With this in mind, emerging adults still engage in prosocial behavior toward family (e.g., defending a sibling who is being picked on, including a parent who is being left out of a family discussion) as they seek reciprocity in their familial relationships (Stanca et al. 2009). These assertions are supported by research that indicates global prosocial behavior toward family is typically stable or slightly decreases throughout adolescence (Eberly et al. 1993) but often rebounds into adulthood (Padilla-Walker et al. 2017).

Available research on prosocial behavior toward friends suggests increases over time (Padilla-Walker et al. 2015), and one study found that emerging adults followed varying trajectories where some helped friends (as well as unidentified others) at either stable or increasing rates (Kanacri et al. 2014). Given the increased salience of friendships during adolescence and emerging adulthood, it is likely that emerging adults (like adolescents) have the opportunity to defend and include their friends more often than other targets (by sheer time spent together), though we are aware of no research that has specifically explored defending and including friends during the transition to adulthood. However, given the potential expansion of the friendship network as adolescents leave high school and the parental home and enter the workforce or a college setting, opportunities for sticking up for a friend who is being mistreated or including someone who feels lonely may become increasingly frequent.

Strangers, or individuals the emerging adult does not know, are perhaps the most commonly studied prosocial target. Previous research shows prosocial behavior toward strangers increases into late adolescence but then decreases from age 18 through the early 20's (Eisenberg et al. 2005), while more recent research suggests that global prosocial behavior toward strangers increases slightly from approximately age 18 to age 20 (Padilla-Walker et al. 2017). Research on volunteering (which is a specific type of prosocial behavior toward strangers) has also found gradual age-related decreases in volunteering from ages 18-26 (Wray-Lake et al. 2017), whereas research on civic engagement has found that emerging adults are actively involved in prosocial behavior toward strangers, much of which is time-intensive (e.g., Teach for America, study abroad) and encompasses clear aspects of defending and including (Hart and VanGoethem 2017). This body of research suggests that even though overall levels of some forms of prosocial behavior toward strangers decline during the transition to adulthood, emerging adults may be in a unique position to be involved in high-cost prosocial behavior because they have fewer family ties and responsibilities than do adolescents or adults (Padilla-Walker and Nelson 2017). Taken together, the research indicates that target is important to consider when exploring levels and change in defending and including during the transition to adulthood.

\section{Types of prosocial behavior}

Research on the multidimensionality of prosocial behavior also stresses the importance of considering different types of prosocial behavior, such as emotional support, sharing, and helping. Less frequently studied types of prosocial behavior include defending and including, which may be especially important in building relationships and contributing to the community as young people become more civically-minded and engage in the current political climate in the United States of America. Indeed, emerging adulthood is a unique time of transition when youth are increasingly self-reliant, autonomous (Lamborn and Groh 
2009), and beginning to follow trajectories that denote floundering or flourishing (Nelson and Padilla-Walker 2013). As such, defending and including behaviors are particularly worthy of study during the transition to adulthood (e.g., Barry et al. 2008) because engagement in these behaviors likely signifies youths' interest in and commitment to their communities and the individuals around them. Furthermore, engagement in various types of prosocial behavior (e.g., volunteering, civic and political engagement, environmentalism) during late adolescence and emerging adulthood has been found to set a trajectory of flourishing into adulthood (e.g., see Faust and Flanagan 2017; Hart et al. 2007), making the transition to adulthood a paramount age at which to promote engagement in a variety of prosocial behaviors. Though research on prosocial development has rarely considered defending and including specifically, theoretical and conceptual models have noted the importance of distinguishing between relatively highand low-cost prosocial behavior (Eisenberg and Spinrad 2014). High-cost prosocial behaviors are those that require some sort of expenditure from the individual (e.g., money, time, emotional capital) such as moral courage or personal burden (Kayser et al. 2010; Padilla-Walker and Fraser 2014). Defending and including behaviors seem to clearly meet these criteria as they often require the risk of social and emotional capital, as well as moral courage.

Defenders generally include those "who stand up for... victims and intervene to defend and help them" (Gini et al. 2008, p. 94). Including is defined as assimilating a previously excluded or outside individual (i.e., a member of an outgroup) into a group context or activity (e.g., Hung and Paul 2006). Despite the important nature of these two forms of prosocial behavior, there is very little research of which we are aware that analyzes their occurrence over time or during the transition to adulthood, so we will also draw on research that focuses on high-cost prosocial behavior as we identify factors that may promote defending and including. Past work suggests that defending and including behaviors are important because they may signify the development of general morality (Gini et al. 2011) and moral identity (Hung and Paul 2006). Research suggests that high-cost helping behaviors (e.g., including and defending) are often preceded by emotional, cognitive, and individual factors. For instance, high-cost prosocial behaviors are generally more consistently associated with sympathy (Eisenberg and Spinrad 2014) and internalized values (Padilla-Walker and Fraser 2014) than are low-cost behaviors. In addition, selfesteem has been linked to high cost prosocial behavior toward strangers (Fu et al. 2017), and self-efficacy (Gini et al. 2008) has been linked to defending behavior. Research on community and civic engagement during the transition to adulthood also suggests that relational factors such as stronger familial relationships (O’Connor et al. 2011) and maternal involvement (Smetana and Metzger 2005) precede high-cost helping behaviors.

Taken together, theoretical models of moral identity suggest that a combination of emotional (sympathy), cognitive (personal values), individual (self-esteem), and relational (maternal warmth) factors contribute to relatively high-cost prosocial behaviors (e.g., volunteering; Hart et al. 1998). Thus, we explored the development of these factors during adolescence as potential correlates of later profiles of defending and including behavior. We also expected that those with profiles displaying consistently high degrees of defending and including would report different levels of emotional, cognitive, individual, and relational strengths than emerging adults who displayed lower levels of defending and including.

\section{Current Study}

The purpose of the current study was to explore defending and including behaviors during the transition to adulthood by addressing three different research questions: (1) What is the prevalence and longitudinal change in defending and including behaviors toward multiple targets during the transition to adulthood? (2) Are there profiles of emerging adults with differing patterns of defending and including behaviors? (3) What adolescent variables (sympathy, selfesteem, benevolent values, maternal warmth) might distinguish between profiles of defending and including during the transition to adulthood?

Because of mixed findings in existing longitudinal research, we found it difficult to make specific hypotheses regarding how defending and including would change over time toward the three targets. However, given the focus on relatively high profile activism among young people in recent years, we expected rates to possibly be high and increasing over time, especially toward strangers. We also explored gender differences in longitudinal trajectories. Many studies indicate that girls and women generally have higher mean levels of prosocial behavior than do men (Eisenberg et al. 2015), though gender differences vary by the type of prosocial behavior. For example, men are more likely to perform heroic, physically dangerous tasks than are women (Carlo and Randall 2002), and one study found no gender differences in defending and including behaviors during emerging adulthood (Nielson et al. 2017). It also seems the pressure that college-aged individuals feel to differentiate by gender roles and characteristics diminishes during this stage in life (Marcell et al. 2011). Thus, whereas gender differences in prosocial behavior are consistently found (favoring females), we thought it possible that gender differences may not be extreme in defending and including behaviors across the transition to adulthood. 
For our second research question, again, there is no research to support specific hypotheses, but we used profile analysis to explore whether there would be different profiles of defending and including behavior at all four ages. It is possible that emerging adults who are greatly involved in these high-cost behaviors represent a relatively small proportion of emerging adults overall, so a person-centered approach that allows for heterogeneity will help us to explore this possibility. Our third research question sought to explore adolescent variables that might promote highcost prosocial behaviors and distinguish between profiles or groups of emerging adults. We expected that emerging adults who had higher levels of sympathy (Eisenberg et al. 2015), self-esteem (Brown and Smart 1991), benevolent values (Schwartz 2009), and maternal warmth (Barry and Wentzel 2006) would also display high levels of defending and including.

\section{Methods}

\section{Participants}

Participants were taken from the Flourishing Families Project, which is a longitudinal study of family life and adolescent development. The project included 500 adolescents ( $M$ age at Time 1, 11.25, 52\% female). In the current sample, $33 \%$ of adolescents came from single-parent families, with $70 \%$ White, $12 \%$ African American, and $18 \%$ multi-ethnic. Average annual income was $\$ 60,000$, although $25 \%$ of the sample reported an annual income below $\$ 36,000$. Data for the current study were taken from Waves 6-10 and restructured by age in order to maximize the available data (each wave had an approximately 4 year age range). The final sample included 469 individuals (94\% longitudinal retention) with full information maximum likelihood in MPLUS used to deal with missing values. Predictors of defending and including were considered at age 16 because self-esteem and values were not measured after that age, and on these variables there were less than $5 \%$ missing data. None of the variables of interest differed as a function of longitudinal attrition. Data were collected in the summers when individuals were ages 16-21; at age 18 about $60 \%$ had just graduated high school and $20 \%$ reported being in college. By age 19 about $70 \%$ reported being in college, and by age 21 about $60 \%$ reported being in college, though only $4 \%$ reported having completed college.

\section{Procedures}

Participant families were selected from a Northwestern city in the United States and were interviewed during the summer of 2007 for the initial time point, and approximately 1 year apart for all other time points (final time point was 2016). Families were randomly selected from targeted census tracts that mirrored the socioeconomic and racial stratification of reports of local school districts, and were contacted directly using a multistage recruitment protocol. All families with a child between the ages of 10 and 14 living within target census tracts were deemed eligible to participate in the study. Of the 692 eligible families contacted, 423 agreed to participate, resulting in a $61 \%$ response rate at the initial time point. In an attempt to more closely mirror the demographics of the local area, a limited number of families were recruited into the study through other means (e.g., referral, fliers; $n=77,15 \%$ ), resulting in 500 total families participating at Time 1 . For the first five waves of data collection interviewers visited the family's home and administered questionnaires. For subsequent waves, questionnaires were completed online.

\section{Measures}

\section{Defending and including behavior}

Participants completed two subscales at ages 18, 19, 20, and 21 from a multidimensional measure of prosocial behavior (Nielson et al. 2017) that assessed defending (4 items, $\alpha$ range .81-.87; e.g., "If someone is being made fun of, I stick up for that person") and including (4 items, $\alpha$ range .76-.84; e.g., "If someone is new to a group, I make an effort to include that person") behaviors. Participants were asked to answer these questions separately for family members, friends, and strangers on a 5-point Likert scale ranging from 1 (not like me at all) to 5 (very much like me). Higher scores were indicative of more defending and including.

\section{Sympathy}

Adolescents' sympathy was assessed at age 16 using a 7item self-report measure ( $\alpha=.81$; Davis 1983). The Likerttype response scale ranged from 1 (strongly disagree) to 5 (strongly agree) and higher scores indicate greater sympathy. Sample item: "When I see someone being taken advantage of, I feel kind of protective towards them."

\section{Self-esteem}

Adolescents' self-esteem was assessed at age 16 using the Rosenberg Self-Esteem Scale (Rosenberg 1965). Adolescents responded to 10 items $(\alpha=.93)$ on a 5-point Likerttype scale ranging from 1 (strongly disagree) to 5 (strongly agree). Sample items include, "I certainly feel useless at times" and "on the whole, I am satisfied with myself." Five 
negative items were reverse coded with higher mean scores representing higher self-esteem.

\section{Benevolence values}

Adolescents' benevolence values were assessed at age 16 using four items $(\alpha=.81)$ taken from the benevolence subscale of the Portrait Values Questionnaire (PVQ; Schwartz et al. 2001). Participants rated how much they thought a description of a fictional person was similar to them, with statements designed to assess the value of benevolence. A 6-point Likert scale was used with response categories ranging from 1 (not like me at all) to 6 (very much like me) and sample items included, "It's very important to this person to help the people around them" and "This person wants to care for the well-being of others".

\section{Maternal warmth}

Maternal warmth was measured at age 16 using a 5-item warmth/support subscale from the Parenting Styles and Dimensions Questionnaire-Short Version ( $\alpha=.81$, PSDQ, Robinson et al. 2001). Adolescents were asked how often their mother did certain behaviors relating to warm/supportive parenting, such as "My mother gives comfort and understanding when I am upset." Responses range on a five point Likert-type scale from 1 (never) to 5 (always), with higher scores indicating higher levels of warm/supportive parenting.

\section{Analysis Plan}

Our first research question addresses the prevalence and longitudinal change in defending and including behaviors toward multiple targets during the transition to adulthood. We conducted three separate growth curve analyses (for behavior toward family, friends, and strangers) for both defending and including behaviors (from ages 18-21). Using the MODEL TEST command in MPLUS, growth curve intercepts and slopes were constrained to be equal for males and females to determine if starting values or trajectories were different as a function of gender. Then, for each behavior (defending and including), a model was created with all three growth curves together (family, friend, and stranger). Intercepts and slopes were constrained to be equal across targets to see if model fit decreased upon constraint, which would suggest whether starting values or trajectories were different for the different targets.

For our second research question we used personcentered analyses (profile analysis in MPLUS) to determine whether there are different profiles of emerging adults who might show differing patterns of defending and including behaviors. Traditional variable-centered statistical approaches are used with the assumption that a sample is drawn from a single population, homogeneous in regard to the parameters of interest, while person-centered approaches are able to identify groups of individuals who are similar or who share a set of characteristics. Thus, we conducted four different latent profile analyses (at ages 18, 19, 20, and 21) using defending and including behaviors toward all three targets. To determine the number of classes, we examined the Bayesian Information Criterion (BIC) and the sample size adjusted BIC (SABIC). The BIC favors models with few parameters and smaller sample sizes (Tofighi and Enders 2008), and the SABIC adds an adjustment to reduce the sample size penalty. We also employed the LMR and adjusted LMR test (which provide a $p$-value to determine if the current model fits better than a model with k-1 classes), examined class sizes, and took entropy (a measure of how well cases are classified) into account (Grimm et al. 2016).

Our third research question was which adolescent variables (gender, sympathy, self-esteem, benevolent values, maternal warmth) might distinguish between profiles of defending and including during the transition to adulthood. Thus, once the profile analysis was completed as specified above, the 3 step approach in MPLUS was used to conduct multinomial logistic regressions (Asparouhov and Muthén 2014). Class membership was regressed onto predictors of class membership, including gender, sympathy, self-esteem, benevolent values, and maternal warmth.

\section{Results}

\section{Descriptive Statistics}

Table 1 contains descriptive statistics for all defending and including behaviors toward all three targets at ages 18-21. Though not noted in the table, we also conducted intercorrelations between defending and including behaviors toward the three targets. They ranged from .23 to $.70, p$ $<.001$, which suggested moderate to strong correlations between defending and including behaviors toward all targets.

\section{Trajectories of Defending and Including Behaviors}

\section{Growth curves for defending behavior}

The growth curve for defending behavior toward family had adequate model fit $\left(X^{2}(4)=3.70, p>.05, \mathrm{CFI}=1.00\right.$, $\mathrm{RMSEA}=.00)$ with a significant intercept $(\mathrm{I}=4.19, p$ $<.001)$ and negative slope $(\mathrm{S}=-.11, p<.001)$. The growth curve for defending behavior toward friends also had adequate model fit $\left(X^{2}(4)=2.72, p>.05, \quad \mathrm{CFI}=1.00\right.$, 
Table 1 Descriptive statistics of defending and including at ages $18-21$

\begin{tabular}{llll}
\hline & $M(\mathrm{SD})$ & & $M(\mathrm{SD})$ \\
\hline Defending18F & $4.12(.80)$ & Including18F & $4.22(.72)$ \\
Defending19F & $4.09(.79)$ & Including19F & $4.21(.68)$ \\
Defending20F & $3.96(.79)$ & Including20F & $4.09(.70)$ \\
Defending21F & $3.95(.77)$ & Including21F & $4.04(.73)$ \\
Defending18FR & $4.20(.67)$ & Including18FR & $4.23(.65)$ \\
Defending19FR & $4.13(.71)$ & Including19FR & $4.25(.62)$ \\
Defending20FR & $4.06(.74)$ & Including20FR & $4.20(.59)$ \\
Defending21FR & $3.99(.73)$ & Including21FR & $4.14(.62)$ \\
Defending18S & $3.38(.82)$ & Including18S & $3.98(.70)$ \\
Defending19S & $3.35(.80)$ & Including19S & $3.95(.71)$ \\
Defending20S & $3.26(.83)$ & Including20S & $3.81(.78)$ \\
Defending21S & $3.16(.82)$ & Including 21 S & $3.68(.86)$ \\
\hline
\end{tabular}

Numbers after variables represent the child's age

$F$ family, $F R$ friend, $S$ stranger

RMSEA $=.00)$ with a significant intercept $(\mathrm{I}=4.21, p$ $<.001)$ and negative slope $(\mathrm{S}=-.07, p<.001)$. Finally, the growth curve for defending behavior toward strangers had adequate model fit $\left(X^{2}(4)=2.13, p>.05, \mathrm{CFI}=1.00\right.$, RMSEA $=.00)$ with a significant intercept $(\mathrm{I}=3.44, p$ $<.001)$ and negative slope $(\mathrm{S}=-.11, p<.001)$. For all three growth curves, intercept and slope were constrained to be equal for men and women, but this did not result in a decrease in model fit, which suggests that initial values and trajectories were not significantly different for males and females. When all three growth curves were combined and intercept and slope terms were constrained to be equal across target, model fit decreased when the intercept of family or friends was constrained to equal the intercept of strangers, but no other constraints resulted in a decrease in model fit. In other words, the intercept of family and friends for defending behavior was significantly higher than was the intercept toward strangers, but all three targets decreased over time at a similar rate (see Fig. 1).

\section{Growth curves for including behavior}

The growth curve for including behavior toward family had adequate model fit $\left(X^{2}(4)=2.96, p>.05, \mathrm{CFI}=1.00\right.$, $\mathrm{RMSEA}=.00)$ with a significant intercept $(\mathrm{I}=4.27, p$ $<.001)$ and negative slope $(\mathrm{S}=-.09, p<.001)$. The intercept and slope were constrained to be equal for men and women, but this did not result in a decrease in model fit, which suggested that trajectories were not significantly different for males and females (see Fig. 2). The growth curve for including behavior toward friends also had adequate model fit $\left(X^{2}(4)=3.41, p>.05, \mathrm{CFI}=1.00\right.$, RMSEA $=.00)$ with a significant intercept $(I=4.24, p$

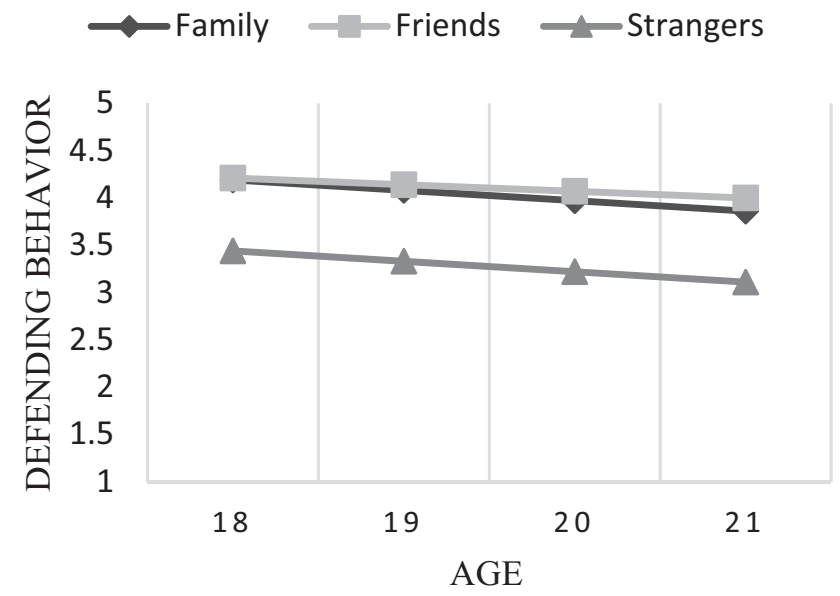

Fig. 1 Trajectories of defending behavior toward family, friends, and strangers

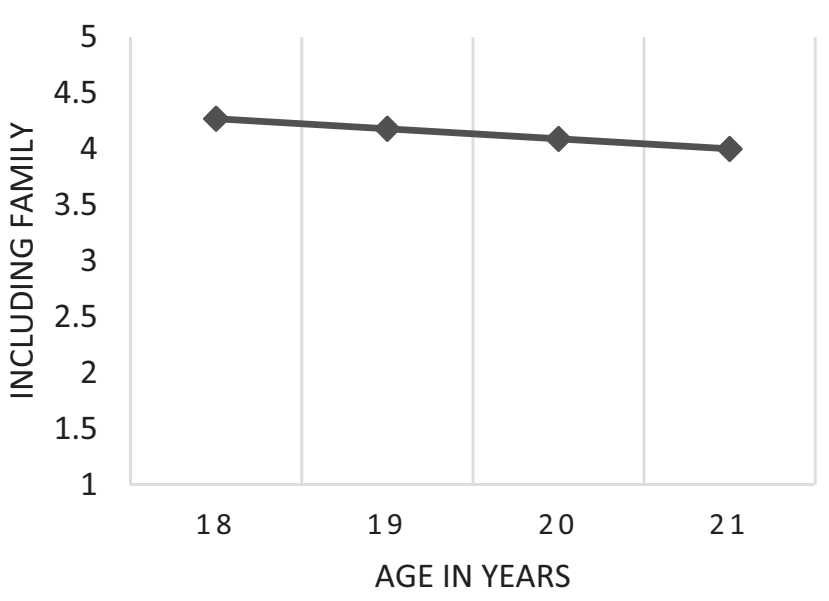

Fig. 2 Trajectory of including behavior toward family

$<.001)$ and non-significant slope $(\mathrm{S}=-.02, p=.25)$. The intercept and slope were constrained to be equal for men and women, which resulted in a decrease in model fit, suggesting that the intercept for including toward friends was higher for women $(I=4.35, p<.001)$ compared to men $(\mathrm{I}=4.11, p<.001)$, and the slope for women was negative and significant $(\mathrm{S}=-.06, p<.05)$, while the slope for men was non-significant $(\mathrm{S}=.03, p=.30$; see Fig. 3). Finally, the growth curve for including behavior toward strangers had adequate model fit $\left(X^{2}(4)=6.75, p>.05, \mathrm{CFI}=.98\right.$, RMSEA $=.04)$ with a significant intercept $(\mathrm{I}=4.04, p$ $<.001)$ and negative slope $(\mathrm{S}=-.13, p<.001)$. The intercept and slope were constrained to be equal for men and women, and only the constraining of the intercept resulted in a decrease in model fit, which suggested that the intercept for including toward strangers was higher for women $(\mathrm{I}=$ $4.13, p<.001)$ compared to men $(\mathrm{I}=3.94, p<.001$; see Fig. 4). 


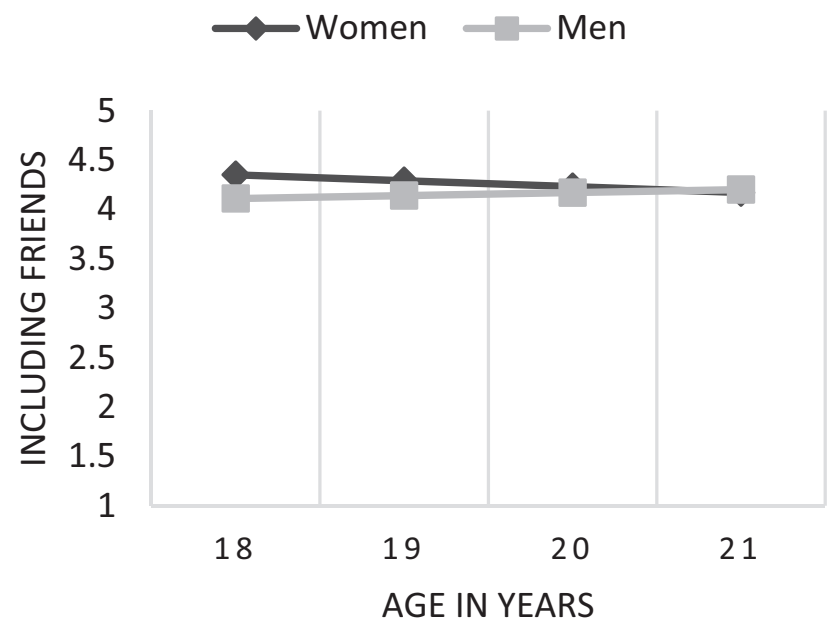

Fig. 3 Trajectory of including behavior toward friends

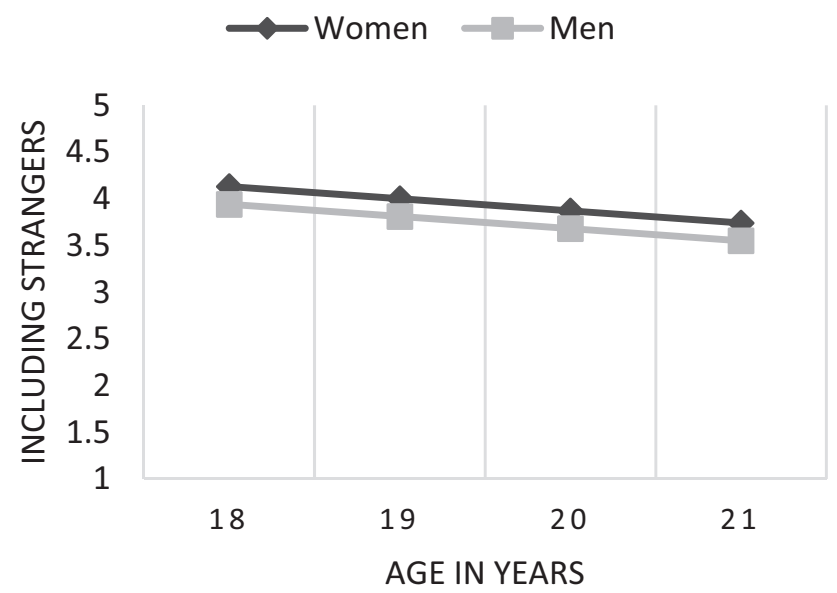

Fig. 4 Trajectory of including behavior toward strangers

When all three growth curves were combined and intercept and slope were constrained to be equal across target, model fit decreased significantly. The intercept of family and friends for including behavior was significantly higher than was the intercept toward strangers. Model fit also decreased when the slope of family or strangers was constrained to be equal to that of friends. These results suggest that the intercept of including toward family and friends is higher than it is for strangers, and including behavior toward family and strangers decreases at a similarly negative rate, which is a slightly steeper decrease than inclusion toward friends.

\section{Profile Analysis for Defending and Including Behaviors}

To address our second research question we used latent profile analysis to explore heterogeneity in both defending and including behaviors toward all three targets (defending
Table 2 Latent profile analysis for defending and including at ages $18-21$

\begin{tabular}{|c|c|c|c|c|c|c|}
\hline Classes & $n$ & Entropy & $\mathrm{BIC}$ & SABIC & LMR & aLMR \\
\hline \multicolumn{7}{|c|}{ Relative model fit by number of classes at age 18} \\
\hline 2 & 120,159 & .83 & 4370.90 & 4310.65 & - & - \\
\hline 3 & $\begin{array}{l}30,117 \\
132\end{array}$ & .84 & 4288.75 & 4206.75 & $p=\mathbf{. 0 8}$ & $p=.09$ \\
\hline 4 & $\begin{array}{l}38,16,96, \\
129\end{array}$ & .84 & 4263.37 & 4158.73 & $p<.01$ & $p<.01$ \\
\hline \multicolumn{7}{|c|}{ Relative model fit by number of classes at age 19} \\
\hline 2 & 118,271 & .84 & 6140.06 & 6079.78 & - & - \\
\hline 3 & $\begin{array}{l}41,153 \\
195\end{array}$ & .84 & 5972.24 & 5889.74 & $p=\mathbf{. 0 2}$ & $p=\mathbf{. 0 3}$ \\
\hline 4 & $\begin{array}{l}46,128 \\
101,114\end{array}$ & .75 & 5948.28 & 5843.58 & $p=.11$ & $p=.11$ \\
\hline \multicolumn{7}{|c|}{ Relative model fit by number of classes at age 20} \\
\hline 2 & 112,232 & .81 & 5427.13 & 5366.86 & - & - \\
\hline 3 & $\begin{array}{l}51,165 \\
128\end{array}$ & .80 & 5289.56 & 5207.08 & $p<.01$ & $p<. \mathbf{0 1}$ \\
\hline 4 & $\begin{array}{l}43,168 \\
12,121\end{array}$ & .84 & 5273.83 & 5169.14 & $p=.31$ & $p=.32$ \\
\hline \multicolumn{7}{|c|}{ Relative model fit by number of classes at age 21} \\
\hline 2 & 82,85 & .82 & 2655.22 & 2595.06 & - & - \\
\hline 3 & $17,80,70$ & .86 & 2612.65 & 2530.33 & $p=. \mathbf{1 1}$ & $p=. \mathbf{1 1}$ \\
\hline 4 & $\begin{array}{l}20,52,30, \\
65\end{array}$ & .83 & 2607.30 & 2502.82 & $p=.52$ & $p=.52$ \\
\hline
\end{tabular}

Bolded values represent final model

$F$ family, $F R$ friends, $S$ strangers

toward family, friends, and strangers; including toward family, friends and strangers). We conducted four separate mixture models at age 18,19,20, and 21 to see if profiles were similar at different ages. Two, three, and four-class models were estimated. As shown in Table 2, fit statistics at each age suggested a three class solution. In certain instances, some fit statistics recommended different models, but most models across the four ages favored the three-class solution. Furthermore, four-class solutions were not meaningfully different than three-class and had relatively small class sizes, thus we opted to interpret the three-class solution at each age for parsimony and interpretability.

All four ages consisted of classes that were remarkably similar (see Fig. 5). At all ages the smallest class (11\% age $18,10 \%$ age $19,15 \%$ age $20,10 \%$ age 21 ) consisted of individuals who were well below the mean on all six aspects of prosocial behavior, with slightly elevated levels of defending toward strangers. Thus, we refer to this class as those with low levels of defending and including behaviors (or low levels of high-cost behaviors). The second class at all ages $(42 \%$ at $18,40 \%$ at $19,48 \%$ at $20,48 \%$ at 21$)$ consisted of individuals who were just below the mean on all six aspects of prosocial behavior, with few variations by 
Profiles at Age 18
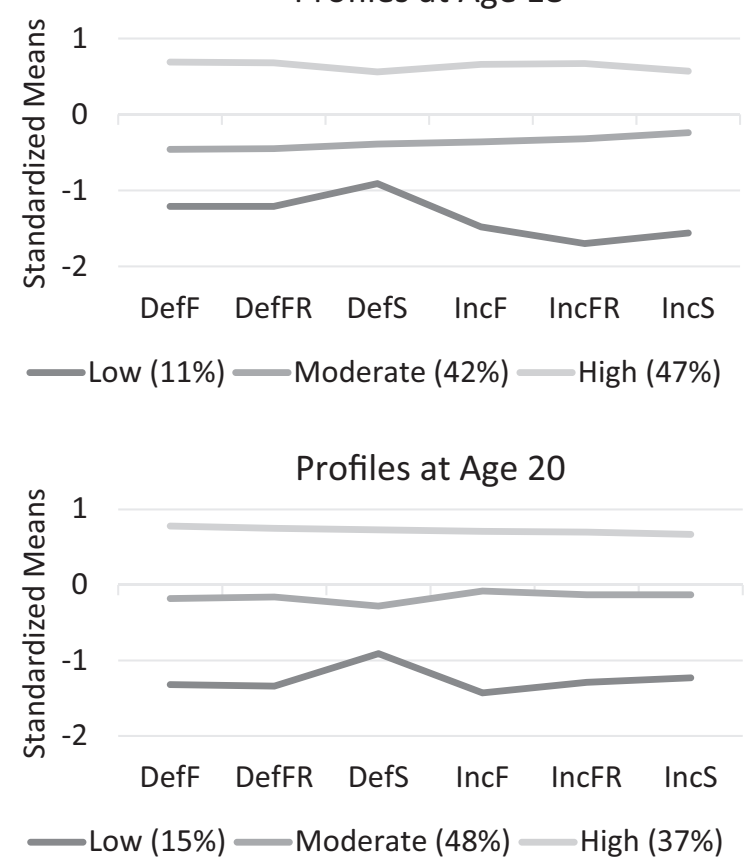

Profiles at Age 19

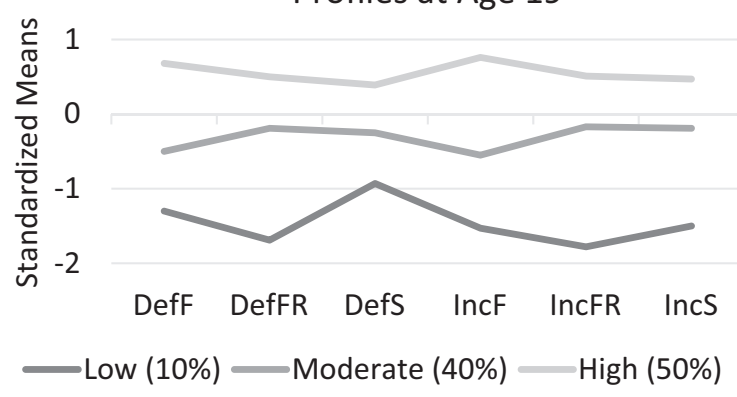

Profiles at Age 21

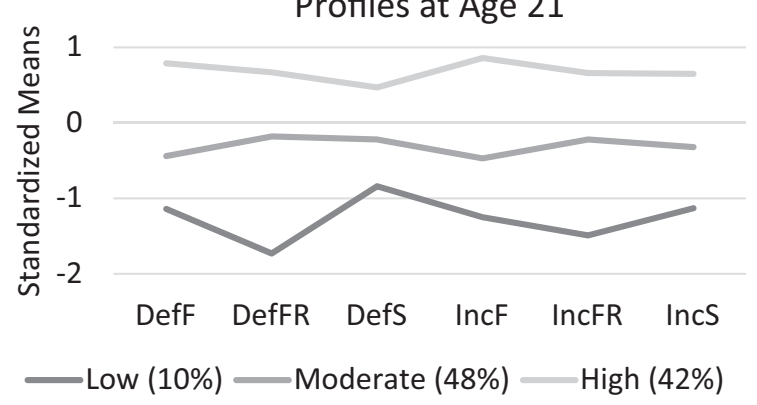

Note. $\mathrm{F}=$ Family, $\mathrm{FR}=$ Friends, $\mathrm{S}=$ Strangers

Fig. 5 Latent profile analysis of defending and including at ages 18-21

type or target. Thus, we refer to this class as those with moderate levels of defending and including behavior. The third class at all ages $(47 \%$ at $18,50 \%$ at $19,37 \%$ at 20 , $42 \%$ at 21) consisted of individuals who were above the mean on all six aspects of prosocial behavior, thus we refer to this class as those with high levels of defending and including behaviors. Taken together, a small proportion of emerging adults seem to display low levels of defending and including, whereas close to half display moderate or high levels.

\section{Predictors of Class Membership}

To address our third research question, we explored whether gender, sympathy, self-esteem, benevolent values, and maternal warmth at age 16 distinguished between the three classes found in person-centered analyses above. Because of patterns of missing data between the predictors and classes at age 18 (due to data restructuring), we could not use the 3-step approach because it utilizes listwise deletion of missing data on auxiliary variables. Thus, we only explored differences at ages 19, 20, and 21. The base category was switched across regressions to make all pairwise comparisons (see Table 3). Though there were no patterns that were found across all three ages, we will first interpret those that were found for at least two ages. Notably, those individuals in the high class had higher levels of sympathy and benevolent values than those in the low class, and higher self-esteem than those in the moderate class. There were no consistent differences between those in the low and moderate class across at least two ages, but those in the moderate class at age 19 had higher levels of maternal warmth than did those in the low class at age 19, and those in the moderate class at age 20 had higher levels of sympathy and benevolent values than those in the low class at age 20 . Gender did not statistically differentiate between any of the classes.

\section{Discussion}

The transition to adulthood is often characterized by a redefinition of relationships with parents and friends, as well as increased interactions with strangers and the prospect of forming new relationships. Because of expanded interactions that occur as a result of leaving the parental home and/or starting work or schooling without the responsibilities inherent in having a family of their own, emerging adults may have increased occasion in a variety of relationships to engage in high-cost prosocial behaviors such as defending and including others (e.g., Hart and van Goethem 2017; Watson 2014). Indeed, the media continues to highlight examples of young people engaging in highcost prosocial behaviors, but we know little about the actual 
Table 3 Logistic regression parameters predicting class membership at ages 19,20, and 21we don't actually need the right most column of this table. It can be deleted or I can send a new one without it.

\begin{tabular}{llll}
\hline Comparison $(=1)$ & 1 Low & 2 Moderate & 3 High \\
& $\mathrm{b}(\mathrm{se})$ & $\mathrm{b}(\mathrm{se})$ & $\mathrm{b}(\mathrm{se})$ \\
\hline
\end{tabular}

Age 19

2 (Moderate)

Male $^{\mathrm{a}}$

Sympathy

Self-esteem

Benevolent values

Maternal warmth

3 (High)

Male $^{\mathrm{a}}$

Sympathy

Self-esteem

Benevolent values

Maternal warmth

Age 20

2 (Moderate)

Male $^{\mathrm{a}}$

Sympathy

Self-esteem

Benevolent values

Maternal warmth

3 (High)

Male $^{\mathrm{a}}$

Sympathy

Self-esteem

Benevolent values

Maternal warmth

Age 21

2 (Moderate)

Male $^{\mathrm{a}}$

Sympathy

Self-esteem

Benevolent values

Maternal warmth

3 (High)

Male $^{\mathrm{a}}$

Sympathy

Self-esteem

Benevolent values

$.41(.71)$

$1.62(.66)^{*}$

$.89(.56)$

$-.79(1.34)$

$-.02(.60)$

$-1.07(1.06)$

$-.64(.71)$

$-.37(.60)$

$1.48(.59)^{*}$

$3.77(1.55)^{*}$

$1.60(.92)^{\dagger}$

$1.75(.99)^{\dagger}$

$-.56(.70)$

1.11(.48)*

$-.11(.39)$

$51(.72)$

1.64(.69)*

$.26(.54)$

$.34(.48)$

$-.16(.38)$

\section{$.11(.47)$}

$.02(.53)$

$-.63(.36)$

$-.77(.43)$

$-.06(.32)$

Maternal warmth

${ }^{\mathrm{a}}$ Female $=0$, Male $=1$

$\dagger<.10$; $* p<.05$; ** $p<.01$; *** $p<.001$

prevalence of defending and including among emerging adults and the developmental patterns and antecedents. Thus, using a variable-centered approach, the current study sought to assess longitudinal change in defending and including behavior toward family, friends, and strangers during the transition to adulthood. Using a person-centered approach, the current study also explored whether there were different profiles of emerging adults who might show differing patterns of high-cost prosocial behaviors (i.e., defending and including behaviors), and which adolescent variables might distinguish between these profiles during the transition to adulthood. Current findings suggested that defending and including behaviors were relatively high during emerging adulthood, but decreased slightly from age 18 to age 21 and tended to vary by prosocial target. We also identified three different profiles of defending and including behavior at all four ages, and found a number of adolescent variables that distinguished meaningfully between these profiles. Results suggest that taking a multidimensional perspective and using both variable and person-centered approaches when studying prosocial behavior helps us to better understand the frequency and nuances of these relatively high-cost behaviors that seem to be present during late adolescence and the transition to adulthood.

\section{Longitudinal Change in Defending and Including}

Although past research suggests global prosocial behavior toward strangers and friends increases through adolescence and levels off somewhat during emerging adulthood (e.g., Padilla-Walker et al. 2017), our study found that specific behaviors of prosocial defending and including decreased slightly over this period for most targets (with the exception of men's inclusion of friends). There are several possible explanations for these trends, which are consistent with other examinations of specific high-cost prosocial behaviors during the transition to adulthood (e.g., volunteering, WrayLake et al. 2017). One possibility to explain these findings is that although emerging adults are initially exposed to larger peer groups and more opportunities to engage with strangers after they graduate from high school, their focus on school, career, and romantic relationships may actually provide fewer opportunities for them to defend and include others, especially strangers. The transition to adulthood is also a period of relatively instability (Arnett 2000), with frequent residential, employment, religious, and school changes that may result in fewer structured opportunities and less consistent connections with friends, family members, and strangers. Another possibility for the slight decline in high-cost helping is that emerging adults spend a great deal of time doing solitary activities such as using media (emerging adults report spending more time using media than any other activity, Alloy Media and Marketing 2009) and therefore have fewer opportunities to defend and include. That being said, given the overall high levels of both defending and including at all ages in the current study (even with the slight decline taken into account), it could be 
that during late adolescence and when emerging adults leave the home, they are particularly passionate about defending and including, and are active in social causes, but as time in college or work and relationship demands increase, the rate of involvement in these high-cost prosocial behaviors decreases slightly or is replaced by lowercost prosocial behavior. Future research should explore these possibilities.

In addition, change in defending and including tended to vary based on target. More specifically, we found that emerging adults defended and included family members and friends more frequently than they defended or included strangers, on average. This is in line with previous work that suggests helping those one does not know (i.e., a stranger, an outgroup member) is less common due to sheer lack of opportunity (e.g., Padilla-Walker et al. 2017). Though levels of defending and including toward strangers in the current study were still relatively high, emerging adults may have simply had more opportunities to help those they see more regularly. In line with this reasoning, it is also worth noting that including strangers and family members decreased more sharply during emerging adulthood than did including friends. Since research during late adolescence suggests that teens tend to become more and more exclusive regarding those they choose to spend time with (Urberg et al. 1995), and because a large proportion of emerging adults move out of the parental home after high school, opportunities for including friends are likely more plentiful. Future research should aim to assess the influence of changing social norms on including and defending behavior during the transition to adulthood. In addition, as discussed below, variable centered approaches assessing change over time do not account for potential heterogeneity that may exist within young people as they transition to adulthood, necessitating the addition of person-centered analyses to create a more nuanced picture of development.

\section{Profiles of Defending and Including}

To address this need, our second research question sought to understand if there were different profiles of high-cost helpers when combining defending and including behaviors across all three targets. We explored these relations across all four ages of our sample, and found three very similar groups at each age. The smallest group (roughly 10\% at each age) consisted of individuals for whom all types of prosocial behavior toward all targets were well below the mean, though they did seem to have slightly higher levels of defending toward strangers. A second group, composing $40-50 \%$ of individuals at each age, reported moderate levels (just at or below the mean) on all defending and including behaviors toward all targets. A third group consisted of another $40-50 \%$ of individuals at each age and had high levels of defending and including behaviors across all three targets. In summary, most young people reported either moderate or high levels of defending and including, but there was a small group who reported very low levels. These findings validate and extend variable-centered approaches by highlighting the way that group differences may not be represented by overall mean scores or growth curve trajectories. For example, it is possible that the group of individuals with very low levels of prosocial behavior drag down the overall mean, resulting in the slight decrease we saw over time in the variable-centered approach. Unfortunately, because of a lack of significant variability in the slope of defending and including behaviors, we were unable to explore growth mixture modeling with our current data to consider how these three groups might vary in their trajectories over time, but future research should explore longitudinal change in groups of high-cost helpers.

Our third research question also shed light on how these groups might differ from one another: those with high levels of defending and including behaviors generally had higher levels of sympathy and benevolent values compared to those in the low group. This suggests that those with high levels of defending and including also display character traits associated with a strong moral identity during adolescence (e.g., Hart et al. 1998; Nickerson et al. 2015), and may represent some of those young people who are highlighted by the news media as exemplars of high-cost helping. Those with high levels of defending and including also had higher levels of self-esteem compared to those in the moderate group, which is consistent with past research suggesting that high-cost helping (such as sticking up for someone or including an outgroup member) may be more likely when the individual feels self-confident and capable (Bandura 1977; Caprara and Steca 2005; Lindenmeier 2008). These findings have important implications for interventions with adolescents and emerging adults. It seems that emerging adults who regularly stand up for what they feel is right and step into situations where they could be at risk socially, emotionally, or physically, are motivated by core aspects of morality such as sympathy, values, and self-esteem. Parenting or therapy that is focused on fostering moral emotions, personal values, and self-esteem may promote (among other things), future high-cost helping behaviors, which have been found to be protective against a number of problem behaviors (e.g., aggression, delinquency; Padilla-Walker et al. 2015).

\section{Gender Similarities and Differences}

The strongest gender pattern in this study was one of similarity rather than difference. Four of the six statistical models revealed no significant gender differences in the amount of prosocial behavior reported, nor in the patterns of 
change over time. Women showed significantly higher levels of including behavior toward friends and strangers than did men. This is not unexpected given women's generally higher levels of prosocial behavior (Eisenberg et al. 2015) and cultural pressure for women to be kind and friendly (Eagly 2009). Interestingly, men's inclusion toward their friends was the only trajectory that did not significantly decrease over time. Research on boys' prosocial behavior indicates that they feel pressure to avoid prosocial behavior in early adolescence as it potentially decreases the masculine image they are expected to cultivate (Hine and Leman 2013). As boys proceed through adolescence, this negative masculine pressure seems to lessen and boys' prosocial levels rebound as they head toward the transition to adulthood. Perhaps this is due to the relatively high levels of civic-engagement that are found in emerging adulthood (Hart and van Goethem 2017) and an increasing expectation that boys and men emotionally engage with those around them (Bridges and Pascoe 2014). Taken together, gender was not a salient moderator of change over time or a significant predictor of profiles of high-cost helping, which deviates somewhat from research on general prosocial behavior (Eisenberg et al. 2015) and further encourages the need to study different types of prosocial behavior.

\section{Limitations and Future Directions}

Despite having the strength of a longitudinal design, the current study was not without limitations. For instance, the sample was fairly homogeneous in regard to ethnicity and socioeconomic status. Especially given findings seeking to highlight heterogeneity, research should continue to consider more diverse samples when exploring prosocial development during the transition to adulthood. Another limitation of this study is that all measures utilized were single-reporter, self-report questionnaires. Although selfreport, close-ended measures have been used quite frequently in research that employs adolescent and adult samples and are therefore somewhat meritorious, researchers also emphasize the reliability of other forms of measurement, such as multiple informant surveys, qualitative, or mixed-method approaches (Johnson and Turner 2003). In addition, our measure of defending and including assessed how much the participant agreed with statements about their own prosocial behavior rather than actual frequency of behaviors. While this is rather common in the prosocial literature (Eisenberg et al. 2015), it may provide an overestimate of the actual occurrence of high-cost prosocial behavior. Future research should aim to measure prosocial behavior using frequency measures other than self-report surveys in order to capture an accurate picture with multiple perspectives of prosocial behavior.

\section{Conclusion}

The current study adds meaningfully to our understanding of prosocial development during the transition to adulthood. Research on late adolescence and the transition to adulthood often highlights extreme negative behaviors engaged in by individuals in this age group to the exclusion of evidence indicative of flourishing (e.g., Smith 2011; Twenge 2006). This focus continues despite evidence that the vast majority of young people are flourishing in a variety of ways (e.g., Padilla-Walker and Nelson 2017), and are engaged in relatively high-profile prosocial behaviors (Hart and VanGoethem 2017; Watson 2014). Thus, the current study focused on two unique types of prosocial behavior that might be especially prevalent during the transition to adulthood, namely defending and including behavior. Findings did suggest that these behaviors are relatively common during this developmental period, especially for a subgroup of highly prosocial youth. That being said, this study revealed that both defending and including behavior decrease slightly across the transition to adulthood. Findings also highlighted three groups of emerging adults, one with high, one with moderate, and one with low levels of defending and including behavior. Emerging adults who had high levels of prosocial behavior (nearly $50 \%$ of the sample at all ages) also had high levels of sympathy, values, and self-esteem during adolescence. Taking a nuanced approach to prosocial behavior during the transition to adulthood provides a richer description of helping behaviors and their correlates, paints a clearer picture of the ways in which young people flourish, and identifies how parents and educators might promote positive youth development.

Acknowledgements We thank the Family Studies Center at BYU, the School of Family Life, and the College of Family Home and Social Science at BYU, and we recognize the generous support of the many private donors who provided support for this project. We also thank those families who were willing to spend valuable hours with our team in interviews, and the many students who assisted in conducting the interviews.

Authors' Contributions LPW conceived of the study, organized its design and coordination, performed the statistical analyses, and drafted the manuscript. MME helped draft the manuscript. MN helped to draft portions of the manuscript. All authors read and approved the final manuscript.

\section{Compliance with Ethical Standards}

Conflict of Interest The authors declare that they have no conflict of interest.

Ethical Approval All procedures performed in studies involving human participants were in accordance with the ethical standards of the institutional and/or national research committee and with the 1964 Helsinki declaration and its later amendments or comparable ethical standards. 
Informed Consent Informed consent was obtained from all individual participants included in the study.

\section{References}

Alloy Media \& Marketing. (2009). 9th Annual College Explorer Survey. http://www.marketingcharts.com/television/college-students-spend-12-hoursday-with-media-gadgets-11195/. Accessed 24 May 2017.

Arnett, J. J. (2000). Emerging adulthood: A theory of development from the late teens through the twenties. American Psychologist, 55(5), 469-480.

Asparouhov, T., \& Muthén, B. (2014). Auxiliary variables in mixture modeling: three-step approaches using M plus. Structural Equation Modeling: A Multidisciplinary Journal, 21(3), 329-341. https://doi.org/10.1080/10705511.2014.915181.

Bandura, A. (1977). Self-efficacy: toward a unifying theory of behavioral change. Psychological Review, 84(2), 191-215.

Barry, C. M., Padilla-Walker, L. M., Madsen, S. D., \& Nelson, L. J. (2008). The impact of maternal relationship quality on emerging adults' prosocial tendencies: indirect effects via regulation of prosocial values. Journal of Youth and Adolescence, 37(5), 581-591.

Barry, C. M., \& Wentzel, K. R. (2006). Friend influence on prosocial behavior: the role of motivational factors and friendship characteristics. Developmental Psychology, 42(1), 153-163. https:// doi.org/10.1037/0012-1649.42.1.153.

Bridges, T., \& Pascoe, C. (2014). Hybrid masculinities: new directions in the sociology of men and masculinities. Sociology Compass, 8 (3), 246-258. https://doi.org/10.1111/soc4.12134.

Brown, J. D., \& Smart, S. (1991). The self and social conduct: Linking self-representations to prosocial behavior. Journal of Personality and Social Psychology, 60(3), 368-375. https://doi.org/10.1037/ 0022-3514.60.3.368.

Caprara, G. V., \& Steca, P. (2005). Self-efficacy beliefs as determinants of prosocial behavior conducive to life satisfaction across ages. Journal of Social and Clinical Psychology, 24(2), 191-217.

Carlo, G., \& Randall, B. A. (2002). The development of a measure of prosocial behaviors for late adolescents. Journal of Youth and Adolescence, 31(1), 31-44.

Davis, M. H. (1983). The effects of dispositional empathy on emotional reactions and helping: a multidimensional approach. Journal of Personality, 51(2), 167-184. https://doi.org/10.1111/j. 1467-6494.1983.tb00860.x.

Eagly, A. H. (2009). The his and hers of prosocial behavior: An examination of the social psychology of gender. The American Psychologist, 64(8), 644-658. https://doi.org/10.1037/0003066X.64.8.644.

Eberly, M. B., Montemayor, R., \& Flannery, D. J. (1993). Variation in adolescent helpfulness toward parents in a family context. The Journal of Early Adolescence, 13(3), 228-244. https://doi.org/10. 1177/0272431693013003001.

Eisenberg, N., Cumberland, A., Guthrie, I. K., Murphy, B. C., \& Shepard, S. A. (2005). Age changes in prosocial responding and moral reasoning in adolescence and early adulthood. Journal of Research on Adolescence, 15(3), 235-260. https://doi.org/10. 1111/j.15327795.2005.00095.x.

Eisenberg, N., \& Spinrad, T. L. (2014). Multidimensionality of prosocial behavior: Rethinking theconceptualization and development of prosocial behavior. In L. M. Padilla-Walker, G. Carlo, L. M. Padilla-Walker, G. Carlo (Eds.), Prosocial development: A multidimensional approach (pp. 17-39). New York, NY, US: Oxford University Press.
Eisenberg, N., Spinrad, T. L., \& Knafo-Noam, A. (2015). Prosocial development. In M. Lamb \& C. Garcia-Coll (Eds.) and R. M. Lerner (Vol. Ed.), Handbook of child psychology (7th ed.). New York, NY: Wiley.

Faust, V., \& Flanagan, C. (2017). National service as an institutional pathway to flourishing. In L. M. Padilla-Walker, L. J. Nelson, L. M. Padilla-Walker \& L. J. Nelson (Eds.), Flourishing in emerging adulthood: Positive development during the third decade of life (pp. 269-284). New York, NY, US: Oxford University Press.

Fortuna, K., \& Knafo, A. (2014). Parental and genetic contributions to prosocial behavior during childhood. In L. M. Padilla-Walker, \& G. Carlo (Eds.), Prosocial development: A multidimensional approach (pp. 70-89). New York, NY: Oxford University Press.

Fu, X., Padilla-Walker, L. M., \& Brown, M. (2017). Longitudinal relations between adolescents' self-esteemand prosocial behavior toward strangers. Journal of Adolescence, 57, 90-98.

Gill, A. (1994). An honourable defeat: A history of German resistance to Hitler. New York, NY: Henry Holt \& Co.

Gini, G., Albiero, P., Benelli, B., \& Altoè, G. (2008). Determinants of adolescents' active defending and passive bystanding behavior in bullying. Journal of Adolescence, 31(1), 93-105. https://doi.org/ 10.1016/j.adolescence.2007.05.002.

Gini, G., Pozzoli, T., \& Hauser, M. (2011). Bullies have enhanced moral competence to judge relative to victims, but lack moral compassion. Personality and Individual Differences, 50(5), 603-608. https://doi.org/10.1016/j.paid.2010.12.002.

Grimm, K. J., Ram, N., \& Estabrook, R. (2016). Growth modeling: Structural equation and multilevel modeling approaches. New York, NY: Guilford Publications.

Hart, D., Atkins, R., \& Ford, D. (1998). Urban America as a context for the development of moral identity in adolescence. Journal of Social Issues, 54(3), 513-530. https://doi.org/10.1111/j.15404560.1998.tb01233.x.

Hart, D., Donnelly, T. M., Youniss, J., \& Atkins, R. (2007). High school community service as a predictor of adult voting and volunteering. American Educational Research Journal, 44(1), 197-219. https://doi.org/10.3102/0002831206298173.

Hart, D., \& van, G. (2017). The role of civic and political participation in successful early adulthood. In L. M. Padilla-Walker \& L. J. Nelson (Eds.), Flourishing in emerging adulthood: Positive development during the third decade of life (pp. 139-166). New York, NY: Oxford University Press.

Hine, B., \& Leman, P. J. (2013). The developing relationship between gender and pro-social behaviour. In P. J. Leman \& H. R. Tenenbaum (Eds.), Gender and development (pp. 78-108). New York, NY, US: Psychology Press.

Hung, H., \& Paul, P. V. (2006). Inclusion of students who are deaf or hard of hearing: secondary school hearing students'perspectives. Deafness \& Education International, 8(2), 62-74. https://doi.org/ 10.1002/dei.190.

Johnson, B., \& Turner, L. A. (2003). Data collection strategies in mixed methods research. Handbook of mixed methods in social and behavioral research Thousand Oaks, CA: Sage (pp. 297-319).

Kanacri, B. L., Pastorelli, C., Eisenberg, N., Zuffianò, A., Castellani, V., \& Caprara, G. V. (2014). Trajectoriesof prosocial behavior from adolescence to early adulthood: Associations with personality change. Journal OfAdolescence, 37(5), 701-713.

Kayser, N. D., Greitemeyer, T., Fischer, P., \& Frey, D. (2010). Why mood affects help giving, but not moral courage: Comparing two types of prosocial behaviour. European Journal of Social Psychology, 40(7), 1136-1157.

Lamborn, S. D., \& Groh, K. (2009). A four-part model of autonomy during emerging adulthood: Associationswith adjustment. International Journal Of Behavioral Development, 33(5), 393-401. 
Lewis, J. \& D'Orso, M. (1999). Walking with the wind: A memoir of the movement. Wilmington, MA: Mariner Books.

Lindenmeier, J. (2008). Promoting volunteerism: effects of self-efficacy, advertisement-induced emotional arousal, perceived costs of volunteering, and message framing. Voluntas: International Journal of Voluntary and Nonprofit Organizations, 19(1), 43-65.

Marcell, A. V., Eftim, S. E., Sonenstein, F. L., \& Pleck, J. H. (2011). Associations of family and peer experiences with masculinity attitude trajectories at the individual and group level in adolescent and young adult males. Men and Masculinities, 14(5), 565-587. https://doi.org/10.1177/1097184X11409363.

Nelson, L. J., \& Padilla-Walker, L. M. (2013). Flourishing and floundering in emerging-adult collegestudents. Emerging Adulthood, 1, 67-78.

Nickerson, A. B., Aloe, A. M., \& Werth, J. M. (2015). The relation of empathy and defending in bullying: a meta-analytic investigation. School Psychology Review, 44(4), 372-390.

Nielson, M. G., Padilla-Walker, L., \& Holmes, E. K. (2017). How do men and women help? Validation of a multidimensional measure of prosocial behavior. Journal of Adolescence, 56, 91-106. https://doi.org/10.1016/j.adolescence.2017.02.006.

O'Connor, M., Sanson, A., Hawkins, M. T., Letcher, P., Toumbourou, J. W., Smart, D., \& Olsson, C. A. (2011). Predictors of positive development in emerging adulthood. Journal of Youth and Adolescence, 40(7), 860-874.

Padilla-Walker, L., Carlo, G., (2014). The study of prosocial behavior: Past, present, and future. In: L. M. Padilla-Walker, G. Carlo, (eds.) Prosocial development: A multidimensional approach; prosocial development: A multidimensional approach. (Chapter xiii, 474 Pages, pp. 3-16). New York, NY: Oxford University Press.

Padilla-Walker, L. M., Carlo, G., \& Memmott-Elison, M. K. (2017). Longitudinal change in adolescents' prosocial behavior toward strangers, friends, and family. Journal of Research on Adolescence. https://doi.org/10.1111/jora.12362.

Padilla-Walker, L. M., \& Fraser, A. M. (2014). How much is it going to cost me? Bidirectional relations between adolescents' moral personality and prosocial behavior. Journal of Adolescence, 37 (7), 993-1001.

Padilla-Walker, L. M., Fraser, A. M., Black, B. C., \& Bean, R. (2015). Associations between friendship, sympathy, and prosocial behavior toward friends. Journal of Adolescence, 25, 28-35.

Padilla-Walker, L. M., \& Nelson, L. J. (2017). Flourishing in emerging adulthood: An understudied approach to the third decade of life. In L. M. Padilla-Walker, \& L. J. Nelson (Eds.), Flourishing in emerging adulthood: Positive development during the third decade of life. New York, NY: Oxford University Press.

Robinson, C. C., Mandleco, B., Olsen, S. F., \& Hart, C. H. (2001). The parenting styles and dimensions questionnaire. In B. F. Perlmutter, J. Touliatos \& G. W. Holden (Eds.), Handbook of family measurement techniques: Vol. 3. Instruments and Index (pp. 319-321). Thousand Oaks, CA: Sage.

Rosenberg, M. (1965). Society and the adolescent self-image. Princeton, NJ: Princeton University Press.

Schwartz, S. H. (2009). Basic values: how they motivate and inhibit prosocial behavior. In M. Mikulincer \& P. R. Shaver (Eds.), Prosocial motives, emotions, and behavior: The better angels of our nature (pp. 221-241). Washington, DC: American Psychological Association.

Schwartz, S. H., Melech, G., Lehmann, A., Burgess, S., \& Harris, M. (2001). Extending the cross-cultural validity of the theory of basic human values with a different method of measurement. Journal of Cross Cultural Psychology, 32(5), 519-542. https://doi.org/10. 1177/0022022101032005001.

Settersten, Jr, R. A., \& Ray, B. (2010). What's going on with young people today? The long and twisting path to adulthood. The Future of Children, 20(1), 19-41.

Smetana, J. G., \& Metzger, A. (2005). Family and religious antecedents of civic involvement in middle class African American late adolescents. Journal of Research on Adolescence, 15(3), $325-352$

Smith, C. (2011). Lost in transition: The dark side of emerging adulthood. Washington, DC: Oxford University Press.

Stanca, L., Bruni, L., \& Corazzini, L. (2009). Testing theories of reciprocity: Do motivations matter? Journal of Economic Behavior \& Organization, 71(2), 233-245. https://doi.org/10.1016/j. jebo.2009.04.009.

Tofighi, D., \& Enders, C. K. (2008). Identifying the correct number of classes in growth mixture models. In G. R. Hancock \& K. M. Samuelsen (Eds.), Advances in latent variable mixture models (pp. 317-341). Charlotte, NC: Information Age Publishing.

Twenge, J. M. (2006). Generation me: Why today's young Americans are more confident, assertive, entitled-and more miserable than ever before. New York, NY: Free Press.

Urberg, K. A., Degirmencioglu, S. M., Tolson, J. M., \& HallidayScher, K. (1995). The structure of adolescentpeer networks. Developmental Psychology, 31(4), 540-547.

Watson, E. (2014). Gender equality is your issue too. Speech by UN Women Goodwill Ambassador Emma Watson at a Special Event for the HeForShe Campaign. New York, NY: United Nations Headquarters 20.

Wray-Lake, L., Schulenberg, J., Keyes, K. M., \& Shubert, J. (2017). The developmental course of community service across the transition to adulthood in a national U.S. sample. Developmental Psychology, 53(12), 2397-2408. https://doi.org/10.1037/ dev0000377.

Zimmer-Gembeck, M. J., Geiger, T. C., \& Crick, N. R. (2005). Relational and physical aggression, prosocial behavior, and peer relations gender moderation and bidirectional associations. The Journal of Early Adolescence, 25(4), 421-452. https://doi.org/10. 1177/0272431605279841.

Laura M. Padilla-Walker is a Professor at Brigham Young University and studies the parent-child relationship and media as they relate to prosocial and moral outcomes.

Madison Memmott-Elison is a Phd candidate at the University of Missouri and studies prosocial behavior and self-regulation.Not sure Madison and Matthew should have a 1 after their name, they are not at BYU

Matthew G. Nielson is a Phd candidate at Arizona State University and studies gender development. 
Journal of Youth \& Adolescence is a copyright of Springer, 2018. All Rights Reserved. 